\title{
Realizing an Applied Gaming Ecosystem: Towards Supporting Service-based Innovation Knowledge Management and Transfer
}

Citation for published version (APA):

Becker, J., van Lankveld, G., Steiner, C., \& Hemmje, M. (2015). Realizing an Applied Gaming Ecosystem: Towards Supporting Service-based Innovation Knowledge Management and Transfer. Paper presented at 4th International Conference, GALA 2015, Rome, Italy.

Document status and date:

Published: 06/12/2015

\section{Document Version:}

Peer reviewed version

\section{Document license:}

CC BY-NC-ND

Please check the document version of this publication:

- A submitted manuscript is the version of the article upon submission and before peer-review. There can be important differences between the submitted version and the official published version of record. People interested in the research are advised to contact the author for the final version of the publication, or visit the DOI to the publisher's website.

- The final author version and the galley proof are versions of the publication after peer review.

- The final published version features the final layout of the paper including the volume, issue and page numbers.

Link to publication

\section{General rights}

Copyright and moral rights for the publications made accessible in the public portal are retained by the authors and/or other copyright owners and it is a condition of accessing publications that users recognise and abide by the legal requirements associated with these rights.

- Users may download and print one copy of any publication from the public portal for the purpose of private study or research.

- You may not further distribute the material or use it for any profit-making activity or commercial gain

- You may freely distribute the URL identifying the publication in the public portal.

If the publication is distributed under the terms of Article $25 \mathrm{fa}$ of the Dutch Copyright Act, indicated by the "Taverne" license above, please follow below link for the End User Agreement:

https://www.ou.nl/taverne-agreement

Take down policy

If you believe that this document breaches copyright please contact us at:

pure-support@ou.nl

providing details and we will investigate your claim.

Downloaded from https://research.ou.nl/ on date: 26 Apr. 2023 


\title{
Realizing an Applied Gaming Ecosystem: Towards Supporting Service-based Innovation Knowledge Management and Transfer
}

\author{
Jana Becker ${ }^{1}$, Giel van Lankveld ${ }^{2}$, Christina Steiner ${ }^{3}$, Matthias Hemmje ${ }^{1}$ \\ ${ }^{1}$ Research Institute for Telecommunication and Cooperation, Martin-Schmeisser-Weg 4, \\ 44227 Dortmund, Germany \\ ${ }^{2}$ Open University of the Netherlands, Valkenburgerweg 177, 6419 AT Heerlen, The \\ Netherlands \\ ${ }^{3}$ Graz University of Technology, Inffeldgasse 13, 8010 Graz, Austria \\ \{jbecker, mhemmje\}@ftk.de \\ \{Giel.vanLankveld\}@ou.nl \\ \{christina.steiner\}@tugraz.at
}

\begin{abstract}
The EU-based industry for non-leisure games is an emerging business. As such it is still fragmented and needs to achieve critical mass to compete globally. Nevertheless its growth potential is widely recognized. To become competitive the relevant applied gaming communities and SMEs require support by fostering the generation of innovation potential. The European project Realizing an Applied Gaming Ecosystem (RAGE) is aiming at supporting this challenge. RAGE will help by making available an interoperable set of advanced technology assets, tuned to applied gaming, as well as proven practices of using asset-based applied games in various realworld contexts, and finally a centralized access to a wide range of applied gaming software modules, services and related document, media, and educational resources within an online community portal called the RAGE Ecosystem. It is based on an integrational, user-centered approach of Knowledge Management and Innovation Processes in the shape of a servicebased implementation.
\end{abstract}

\section{Introduction and Motivation}

The European landscape for non-leisure games (applied games or formally called serious games) industries is an emerging market. Contrary to the established video game industry it is still fragmented over a large number of small and independent companies and needs to achieve defined product and service qualities to compete globally. The EU project Realizing an Applied Gaming Ecosystem (RAGE) [1] will support this challenge by building up an applied gaming community portal to promote collaborations and knowledge exchange between and among different stakeholders. The so called RAGE Ecosystem will provide an interoperable set of advanced applied gaming technology assets as well as a bundle of proven practices of using asset-based applied games in various real-world contexts. This will be achieved by enabling a centralized access to a wide range of applied gaming software modules, services and 
related documents, media, and educational resources. The community portal as an online social space will facilitate collaboration, especially under the condition of progress and innovation, between game developers, researchers from multiple disciplines, online publishers, educational intermediaries and end-users and will provide workshops and online training opportunities for developers and educators. [2].

This paper will start to review the objectives of the RAGE Ecosystem, will show the basic considerations influencing the Ecosystem concept and development as well as the economic potential of Ecosystems and the importance of Knowledge Management in the execution of innovation and value added processes.

Therefore, the Knowledge Management fundamental SEKI model will be described supplemented by the extension into an Innovation Knowledge Lifecycle. The realization into the specific technological environment will be shown from a knowledge and a service oriented perspective extended by a short description of the development approach and the evaluation approach. To describe the potentials of the Ecosystem examples of similar, successful Ecosystems from different domains will be introduced and the economic value potential of the asset approach will be taken into account. Finally a conclusion will review the potential outcomes and benefits of the RAGE Ecosystem.

\section{The Objectives of the RAGE Ecosystem}

The main objectives of the RAGE Ecosystem are to allow its participants to get hold of advanced, usable gaming assets (technology push), to get access to the associated business cases (commercial opportunity), to create bonds with peers, suppliers and customers (alliance formation), to advocate their expertise and demands (publicity), to develop and publish their own assets (trade), and to contribute to creating a joint agenda and road-map (harmonization and focus). Therefore, the RAGE project is a technology and know-how driven research and innovation project. Its main driver is to be able to equip industry players (e.g. game developers) with a set of technology resources (so-called assets) and strategies (i.e. know-how) to strengthen their capacities to penetrate an almost new market (non-leisure) and to consolidate a competitive position. In consequence, the RAGE Ecosystem and its integration with social networks of game-developing-, gaming-, and applied-gaming communities will on the one hand become an enabler to harvest community knowledge and on the other hand it will support the access to the RAGE Ecosystem as a knowledge resource for such communities.

The applied gaming sector as an upcoming business market is at present characterized by weak interconnectedness, limited knowledge exchange, absence of harmonising standards, limited specialisations, limited division of labour, and insufficient evidence of the products' efficacies [3] [4]. The industry is scattered over a large number of small, diverse, independent players, niche products and of course specialists. Because of limited collaborations of industries and limited interconnections between industry and research, applied gaming companies display insufficient innovation power and size to open up new markets (e.g. schools, business, 
governments) [3] [2]. To support the development and growth of this branch the RAGE Ecosystem will foster the merging of the heterogeneous applied gaming communities by providing an effective knowledge and innovation management service tool. The Ecosystem will serve as an interactive knowledge and content management platform and provide a diverse set of services across the knowledge value chain [5].

As a single entry point for applied gaming it will realize centralized access to a wide range of applied gaming software modules, services and resources (or their metadata) by the arrangement of a well-managed and structured asset repository, digital library, and media archive system. The resulting material in the Ecosystem, particularly the textual resources, will be semantically annotated to support searching and access. Besides this, the Ecosystem will arrange workshops and offer training courses on an online training portal, covering training for developers and educators in order to amplify applied gaming uptake. The aim will be to support the selfsustainable production of assets and documentation, training material, workshops and collaboration activities. In addition the social dimension of the RAGE Ecosystem will be supported by community tools for collaboration, annotation, creativity, matchmaking. [2]

\section{Knowledge Management and Innovation Processes}

The increase of global competition combined with limited budgets affects the frequency and quality of realizing innovations today. Under the conditions described above, the launch of innovative products for SMEs of the applied gaming industry constitutes an enormous challenge. They need strategies to have the crucial competitive advantage of being faster than others [6]. Accelerating the discovery of new (scientific) findings, the technical realization and the market launch [7] [8] is increasingly dependent on the use of advanced information and knowledge technology for building environments that support the innovation process systematically and efficiently [9]. Such environments depend on a number of advanced Knowledge Management technologies and processes and have to adapt to a wide variety of innovative practices, cultures, organizational context and application areas, where innovation takes place. Independent of the domain, innovation is a knowledge-intensive process. [6]

To support innovation processes successfully, an established Innovation Knowledge Lifecycle has proven to be valuable and essential [10] [6].

\subsection{The SEKI model}

One of the most important bases for these Knowledge Management considerations is the SEKI model from Nonaka and Takeuchi (cf. Fig. 1). SEKI describes four knowledge creation and -transformation processes [11] between tacit and explicit knowledge. The learning effect and the development of the knowledge base results in the so called knowledge spiral, which occurs in several passes of the SEKI process and is described as (organizational) learning [12]. The knowledge spiral differentiate 
between explicit knowledge, which is stored in media and can be recorded, transmitted and stored by means of information and communication technology and tacit knowledge, which is based on ideals, values and feelings of individuals. It is difficult to formulate and to pass on. [13] The core of this model is the interaction between explicit and implicit as well as individual and collective knowledge for the generation of new knowledge and innovation [14].

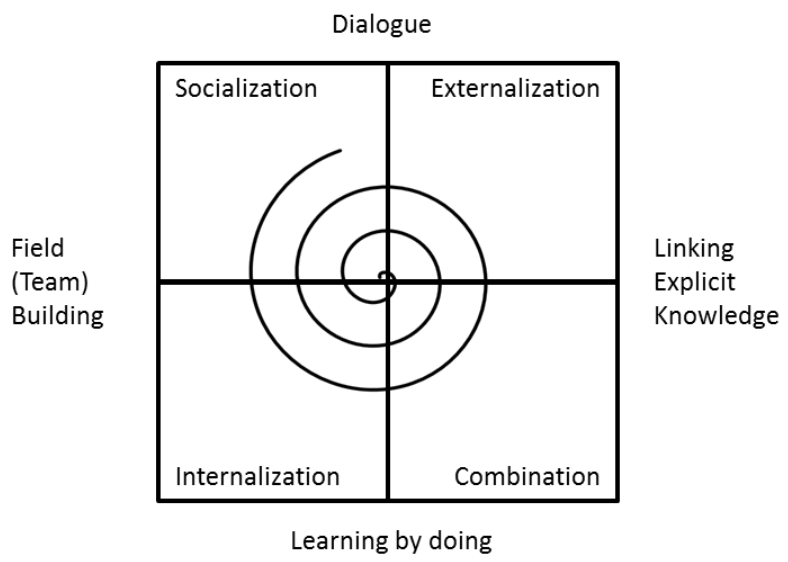

Fig. 1 SEKI Knowledge Spiral [13]

The four steps of the process are described as Socialization, Externalization, Combination and Internalization (SEKI). The cycling of these steps results in the spiral and symbolizes the continuous, dynamic change process of the resource knowledge. [13]

\subsection{The Innovation Knowledge Lifecycle (IKLC) Meta Model}

The IKLC model is integrating the SEKI cycling process in an innovation process environment. The innovation process is thereby influenced by a problem cycle and a knowledge cycle. The problems were composed through market needs, innovation strategies and available resources. In the considerations of this paper problems will be simplified as needs or demand. The concept of the knowledge cycle has special significance. It distinguishes three basic knowledge types: community, organizational knowledge, shared by a specific community or within an organization, and working knowledge, the knowledge at hand in a concrete working or task context. It differs between personal knowledge of an individual or team knowledge as the relevant joint knowledge of the team members. [6]

The innovation process influenced by the demand on the one hand and the working knowledge on the other hand will lead into a demand specific solution. This solution will not necessarily be a tangible product. In the case of RAGE it will be an intangible gain of evaluated and validated knowledge and experiences. 


\section{Realizing the Digital Ecosystem}

The concept of a supporting tool for innovation processes by creating an adequate environment considering incoming needs and demand, working knowledge processes and the satisfied demand based on innovative outcome has been extended to the concept of the RAGE Ecosystem. The environment is located in the domain of applied gaming and the corresponding communities (applied game developers, game based learning initiatives, etc.). That's important because each community or domain is assumed to have its own shared context. Even in the field of applied gaming the different perspectives or "languages" across communities have an impact on the performance of the whole innovation knowledge lifecycle process [15].

\subsection{Knowledge-driven Innovation Approach}

Mapping the SEKI and IKLC ideas onto the Knowledge Management within the RAGE Ecosystem can be described as follows. Driven by the need for competitive products and services, responsive to the customers fast changing requirements the applied gaming industry indicates a high demand of innovation. To establish an appropriate environment and kind of a knowledge-baseline the Ecosystem will collect media resources as well as documentation, training material, and best practices from the heterogeneous and dispersed applied gaming landscape to provide relevant communities the opportunity to participate, to share, and to benefit from these resources and to create new, innovative outcomes. In a first step available explicit as well as tacit knowledge must be made available in machine-readable shape to handle it within a technology-based infrastructure. Therefore, applied gaming users or user groups from a corresponding serious gaming or game based learning community (e.g., software developer, researcher or end-user) have to externalize their tacit needs, requirements, assets, knowledge, information, and experiences into explicit digital content and knowledge objects (text, image, video, recorded speech, taxonomies ...) and provide them to the related applied gaming communities. The RAGE Ecosystem will serve as a platform for this kind of externalization and social sharing. The service can be described as Externalization and Socialization. In the next step a Combination process of merging existing, explicit knowledge from different domains (e.g., Research, Development, Education) generates new information in the context of applied gaming. As one of the features of this system, the digital content objects will be annotated with semantic representations of knowledge objects, as e.g., taxonomies. This means an enrichment of objects with a common framework of semantic annotation supporting understanding of externalized knowledge implicitly contained in digital content, to solve problems of different perspectives or understanding as described above. As a result a systematic search and analysis of content objects and knowledge resources will be possible. Thus, the Ecosystem supports its users to find content arose from tacit knowledge with explicitly annotated semantic representations and to adapt, extend and link it to internalize this knowledge (Internalization). This step is called cognitive value creation or the generation of knowledge. [10]

Connecting to this process the attached Educational Portal offers internalization resp. knowledge transfer in the sense of a learning management process. It serves as a 
huge knowledge library or database. The learning objectives of a user could be annotated, based on his profile, so that this annotations will be available as knowledge in the system additionally. A test / exam can then decide what content needs to be learned in order to achieve the learning objectives and which competences already exist and may be assigned to the users profile.

By working on the solutions experiences will be influencing the results and will appear as results out of the process. This kind of knowledge will complete the working knowledge and the knowledge cycle.

\subsection{Service-driven Innovation Approach}

Taken this features of the RAGE Ecosystem into account the Content- and Knowledge Management Portal is integrating streams of the demand and supply side. Users will be able to inquire community specific knowledge, to search and access knowledge, to consume knowledge and information (e.g., online training courses) and they will be able to produce new media objects and knowledge in various ways.

Thus, the Ecosystem including the offered features receives a Service Character. In this case knowledge represents an intangible commodity and the result of the service process has intangible character. The process could be highly integrative, if the customer, frequently the user itself, will be integrated into the preparation constantly. [16] An advantage of the system lies in the automated execution of the described service processes, the Ecosystem can act efficiently and independently, it arises an automated service.

Considering the Service Production Phase Model [17] [18] knowledge management within the Ecosystem environment will be affected through internal and external factors. The internal factors may be tacit knowledge and experiences of the users of the applied gaming communities or other internal knowledge carriers, the explicit knowledge of already existing recourses and assets organized in the Ecosystems content management infrastructure, the ambition and motivation to create something new and the users capacity. In addition expert knowledge, information and expertise from outside the direct user community have to be taken into account as well as community collaboration support.

The users or user groups will produce a pre-combination of knowledge by combination and integration of content and their experiences from different domains and will supplement this by consultation of external experts or social communities.

The final combination will be resulting by including the customer to the service production process. The customer in this demonstrated knowledge production process will mainly be the user itself. Because of his special demand of knowledge he will enter the Ecosystem and will trigger the knowledge creation process in different ways. Maybe he will inquire more competencies in the field of applied gaming by entering to an online trainings course. Or he will inquire a new serious game based asset and will collaborate with other software developers or he will just learn from the best practice knowhow to create a new idea and bring it efficiently into the market afterwards. 


\subsection{Development Approach}

Based on the previous considerations and to avoid the risk of not working instruments and environment the development will be an agile process involving different stakeholder resp. user communities. In the first step the researcher requests and requirements out of the RAGE consortium will be integrated. Thereafter the game development companies will be involved and in the third step the application partners will be integrated to improve the system. Using these different so called user stereotypes with different interests, experiences and skills, the Ecosystem will be evaluated during the development process. The result is a phase-oriented usercentered agile development approach. The accompanying evaluation process is described in section "6 Evaluating the Ecosystem".

\section{Potentials based on the RAGE Ecosystem}

To strengthen the approach of the RAGE project similar Ecosystems can be referenced and the value of knowledge could be made much more transparent.

\subsection{Similar Ecosystems}

In order to find empirical support for success chances of the RAGE project as an applied gaming Ecosystem similar Ecosystems can be inspected that are not specifically focused on the domain of applied gaming. An example of such an Ecosystem is GitHub ${ }^{1}$.

GitHub is a software development Ecosystem which currently has over 10 million users. Users can upload or start a software project on GitHub and collaborate on its development with other users in the community [19]. Currently active and past projects are retained and can be used as examples and sources of knowledge. GitHub demonstrates that an Ecosystem with a partial overlap of features to the RAGE Ecosystem but with a different domain can be successfully adopted as collaboration environments.

Another example for empirically supporting the potential of the RAGE Ecosystem is the GALA project. The GALA project involves 31 European institutions and facilitates the cultivation and dissemination of academic applied games knowledge [20]. The GALA project resulted in a successful conference; a scholar.google search reveals 37 publications for 2014 as well as a host of GALA related research. One of the relevant differences between RAGE and GALA is that RAGE aims to facilitate the business market rather than the academic community. However, both RAGE and GALA have overlap in residing in the domain of applied gaming.

\footnotetext{
${ }^{1}$ http://www.github.com
} 


\subsection{Economic Value Potential}

To foster the willingness of the addressed communities to participate with RAGE and to strengthen the common understanding of the necessity and usefulness of such an Ecosystem it is important to understand the project ideas behind the expected developments within the Ecosystem. RAGE focus on the creation and exchange of assets that could be incorporated in different games targeting different populations and application fields. Most of the available approaches and methodologies used by game development companies typically focus on design and development of domainspecific games. The RAGE assets are self-contained solutions showing economic value potential based on advanced technologies related to computer games, and intended to be reused in different game platforms. To increase the added value potential value adding services and attributes, like instructions, tutorials, examples and best practices, instructional design guidelines and methodologies, connectors to major game development platforms, data capacity, and content authoring tools for game content creation will be supplemented. RAGE assets will be shared, exchanged, enriched and reused in the field of serious gaming. Looking from a knowledge management perspective the RAGE assets will be developed as a product of a digital knowledge creation- and -transformation process and then flow itself into the production of new applied games or game based learning applications.

Hence, the developed knowledge will be economized and could be monetarily evaluated at the market. Therefore knowledge becomes an economic asset itself and the process of knowledge creation becomes a value added service. Depending on the initial requirements and needs new knowledge arises in the transformation process that can be brought to the market within the meaning of value added. It may be a further qualification of a user or a new asset in the form of an accumulation or enrichment of one or more existing software assets. The user then has an increased competence and thus an increased market value on the applied gaming market. It is planned to underpin this by a certification form of training by the educational portal. The newly gained technology asset could also be monetized in the market, as it flows into the development of new and innovative games.

\section{Evaluating the Ecosystem}

To empirically demonstrate the quality and benefit of the RAGE Ecosystem, it will be systematically investigated in user-oriented evaluation studies. This is part of the holistic RAGE evaluation approach aiming at a comprehensive understanding of the added value of applied gaming technologies for their stakeholders. For a full coverage of the usage and stakeholder dimension of the RAGE technologies - from searching and contributing resources, to developing an applied game, to actually playing it - a multi-perspective evaluation framework is elaborated as a common reference point guiding all evaluation work [19]. For investigating the effectiveness of the RAGE Ecosystem, evaluation approaches from the field of digital libraries and virtual research environments are taken up and adapted [20] [21]. These kinds of information systems and the Ecosystem have the same core feature - i.e. providing information 
and resources through networked systems - and thus, they also share similar factors of system success, like usability, user acceptance, usefulness of resources, and performance. Multi-method evaluations triangulating different data sources (retrospective reports, interaction logs, and online feedback) will be carried out on the Ecosystem. The evaluation studies will iteratively involve the different stakeholder groups and communities, aligned with the phase-centred agile development approach.

\section{Conclusion}

The RAGE Ecosystem will provide a wide range of supporting services in the field of knowledge transfer and -creation to overcome low market access and small market share of small and medium sized companies in the applied games market, to create new effective technology based assets in order to build new ingenious learning games.

The innovation potential of the new platform based knowledge added value process underlies the following factors: a huge, mostly entire collection of community specific knowledge (e.g., content like media objects, software components and best practices), a structured approach of knowledge access, search and browse, collaboration tools as well as social network analysis tools to foster efficient knowledge creation and transformation processes into marketable technology assets.

The RAGE Ecosystem supports therefore the interconnectedness, the knowledge exchange and the harmonization of standards of the applied gaming branch.

Using this support and newly acquired strength, the industry should have the opportunity to assert themselves and their products to big games companies [22].

\section{Acknowledgements and Disclaimer}

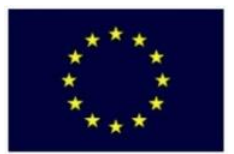

This publication has been produced in the context of the RAGE project. The project has received funding from the European Union's Horizon 2020 research and innovation programme under grant agreement No 644187. However, this paper reflects only the author's view and the European Commission is not responsible for any use that may be made of the information it contains.

\section{References}

[1] „RAGE,“ 2207 2015. [Online]. Available: http://www.rageproject.eu.

[2] RAGE Description of Action, 2015.

[3] J. Stewart, L. Bleumers, J. Van Looy, I. Mariën, A. All, D. Schurmans, K. Willaert, F. De Grove, A. Jacobs und G. Misuraca, The Potential of Digital Games for Empowerment and Social Inclusion of Groups at Risk of Social and Economic Exclusion: Evidence and Opportunity for Policy., Centeno, C. (Ed.), Joint Research Centre, European Commission., 2013.

[4] R. García Sánchez, J. Baalsrud Hauge, M. Oliveira, G. Fiucci, M. Rudnianski, P. Kyvsgaard Hansen, J. Riedel, C. L. Padrón-Nápoles und D. Brown, Business Modelling and Implementation Report 2, 
GALA Network of Excellence, www.galanoe.eu, 2013.

[5] M. Salman, D. Heutelbeck und M. Hemmje, „Towards Social Network Support for an Applied Gaming Ecosystem,“ in The 9th European Conference on Games Based Learning ECGBL 2015, Norway, 2015.

[6] M. Paukert, C. Niederée und M. Hemmje, „Knowledge in Innovation Processes,“ in Encyclopedia of Knowledge Management, 2011.

[7] H.-J. Haß, Die Messung des technischen Fortschritts, München, 1983.

[8] H. Grupp, Messung und Erklärung des technischen Wandels - Grundzüge einer empirischen Innovationsökonomik, Berlin Heidelberg: Springer Verlag, 1997.

[9] G. Specht, C. Beckmann und J. Amelingmeyer, F\&E-Management, Stuttgart: Schäffer-PoeschelVerlag, 2002.

[10] T. Vogel, Wissensbasiertes und Prozessorientiertes Innovationsmanagement WPIM Innovationsszenarien, Anforderungen, Modell und Methode, Implementierung und Evaluierung anhand der Innovationsfähigkeit fertigender Unternehmen, München: Fakultät für Mathematik und Informatik der FernUniversität in Hagen, 2012.

[11] K. North, Wissensorientierte Unternehmensführung. Wertschöpfung durch Wissen., 3. Auflage, Wiesbaden, 2002.

[12] M. Weggeman, Wissensmanagement - der richtige Umgang mit der wichtigsten Ressource des Unternehmens., 1. Auflage, Bonn: MITP-Verlag, 1999.

[13] I. Nonaka und H. Takeuchi, The Knowledge-Creating Company: How Japanese Companies Create the Dynamics of Innovation, Oxford University Press, 1995.

[14] U. Trillitzsch, Die Einführung von Wissensmanagement, Flein b. Heilbronn: Verlag Werner Schweikert, 2004.

[15] M. Paukert, C. Niederée, C. Muscogiuri, P. Bouquet und M. Hemmje, „Knowledge in the innovation process: An empirical study for validating the innovation knowledge life cycle," in Proceedings of the 4th European Conference on Knowledge Management, Oxford, England, 2003.

[16] S. Fließ, Dienstleistungsmanagement: Kundenintegration gestalten und steuern, Gabler Verlag, 2008.

[17] H. Corsten und R. Gössinger, Dienstleistungsmanagement, 5. Auflage, Oldenbourg Wissenschaftsverlag, 2007.

[18] W. H. Engelhardt, M. Kleinaltenkamp und M. Reckenfelderbäumer, „Leistungsbündel als Absatzobjekte," Zeitschrift für betriebswirtschaftliche Forschung, Bde. \%1 von \%245. Jg., Heft 5, pp. 395-426, 1993.

[19] C. Steiner, P. Hollins, E. Kluijfhout, M. Dascalu, A. Nussbaumer, D. Albert und W. Westera, „Evaluation of serious games: A holistic approach,“ in Paper accepted at International Conference of Education, Research and Innovation (ICERI 2015), Sevilla, Spain, 2015.

[20] N. Fuhr, G. Tsakonas, T. Aalberg, M. Agosti, P. Hansen und S. Kapidakis, „Evaluation of digital libraries," International Journal on Digital Libraries, Bd. 8, pp. 21-38, 2007.

[21] C. Steiner, M. Agosti, M. Sweetnam, E.-C. Hillemann, N. Orio, C. Ponchia, C. Hampson, G. Munnelly, A. Nussbaumer, D. Albert und O. Conlan, „Evaluating a digital humanities research environment: the CULTURA approach,“ International Journal on Digital Libraries, Bd. 15, pp. 53$70,2014$.

[22] H.-J. Bullinger, Einführung in das Technologiemanagement - Modelle, Methoden, Praxisbeispiele, Stuttgart: B.G. Teubner, 1994.

[23] H.-J. Bullinger, K. Wörner und J. Prieto, Wissensmanagement heute., Stuttgart: Fraunhofer Institut für Arbeitswirtschaft und Organisation, 1997.

[24] A. de Gloria und I. Roceanu, „Serious Games in the Life Long Learning environment. Games and Learning Alliance Network of Excellence," in The 5th International Conference on Virtual Learning ICVL 2010., 2010.

[25] L. Dabbish, C. Stuart, J. Tsay und J. Herbsleb, „Social Coding in GitHub: Transparency and Collaboration in an Open Software Repository," in Proceedings of the ACM 2012 conference on Computer Supported Cooperative Work, ACM, 2012. 